Vol.: 5 Issue: 2 Date: 31.12.2021 Received: 16.11.2021 Accepted: 15.12.2021 Final Version: 31.12.2021

ISVOS Journal, 2021, 5(2): 182-191 - https://doi.org/10.47897/bilmes.1024513

\title{
Analysis of The Factors Affecting The Density of Vaccine Centers by Fuzzy ELECTRE I Method
}

\author{
Kübra TÜMAY ATEŞ, \\ ${ }^{a, 1}$ Çukurova Üniversitesi, Endüstri Mühendisliği Bölümü, 01330, Adana, Türkiye \\ ORCID ID: 0000-0002-3337-7969
}

\begin{abstract}
Nowadays, the increase in vaccinations due to the epidemic increases the density of health centers and shopping centers, which is another place where vaccinations are made, from time to time. The choice of vaccination sites varies from person to person, and this may increase the density of the vaccination sequence. The criteria that cause the increase in density were created by consulting the health personnel, the people who will be vaccinated and those who have had the vaccine, taking into account the conditions and situations that people care about. Alternatively, three different vaccine centers were selected. These centers are designated as hospitals, health centers and shopping centers. Care has been taken to ensure that the designated vaccination centers are places where daily vaccinations are performed. In order to determine the criteria, the opinions of the people were taken by applying a questionnaire. Thus, in this study, which was conducted for the first time, it was investigated which places were more dense with the determined nine criteria and the parameters affecting this density were tried to be analyzed with the Fuzzy ELECTRE I method. Knowing the reasons for these densities and revealing which institutions people frequently prefer for vaccination can prevent problems.
\end{abstract}

Keywords: "Bulanık ELECTRE I, Karar Verme Metotları, Bulanık Karar Verme"

\section{Giriş}

Dünya var olduğundan beri aşı uygulanmaktadır. Ancak günümüz şartlarındaki durumlar göz önüne alındığında aşılama durumundaki süreç zaman zaman aksayabilmektedir. Bu aksaklıklar, insanların halihazırda aşı yaptırmak istememesi veya aşı yaptırmaktan duyduğu çekincelerden dolayı aşı merkezlerindeki yoğunluk durumunun belirsiz olmasıdır. Covid-19 aşılama oranının dünya çapında yavaşlaması (Cihan, 2021) veya zaman zaman yığılmaların olması bu durumu tetikleyebilmektedir. Bu sebepler dışında, kişilerin aşı sonrası beklenmedik durumlarla karşılaşabileceği endişesi de önemli bir durum haline gelmiştir. Bu nedenlerin oluşturduğu belirsizlikler 1şı̆gında, bu çalışma aşı merkezlerinin yoğunluğunu etkileyen faktörlerin belirlenebilmesine 1şık tutabilecektir. Aynı zamanda aşı olacak kişilerin hangi koşullar altında kendini daha rahat hissettiği ve bu durumla birlikte seçeceği alternatif aşı merkezinin hangisi olacağının belirlenmesinin çıkabilecek olası aksaklıkları öngörmek açısından önemlidir. Bu çalışmada çok kriterli karar verme yöntemlerinden biri olan Bulanık ELECTRE I yöntemi ile aşı merkezlerinin yoğunluğunu etkileyen faktörlerin belirlenebilmesi ve kişilerin aşı yaptırmak için ağırlıklı olarak hangi kurumu tercih ettiği araştırılmıştır. Literatüre bakıldığı zaman karar verme problemlerinin, çok kriterli karar verme metotlarının bulanık mantığa entegre edilmesiyle çözüldüğünü görebiliriz. Bu yöntemler, sorunu çözmek ve sonuçları kantitatif hale getirebilmek için işe yarayan etkin yöntemlerdendir. Bu metotlar arasında, bulanık ELECTRE I -bulanık ELECTRE II, Chang Methodu, bulanık AHP, bulanık TOPSIS, bulanık DEMATEL, DELPHI, bulanık MOORA gibi birçok teknik yer almaktadır.

Akram ve ark., (2020), çalışmalarında bir otel tadilatı için en iyi iç mimar seçimi için Pisagor bulanık TOPSIS (CPF-TOPSIS) yöntemi ve karmaşık Pisagor bulanık ELECTRE I (CPF-ELECTRE I) yöntemi olmak üzere iki yeni model önermiştir. Güler (2012), konaklama sektöründe, getiri yönetimi uygulamalarının başarı faktörlerini genişletilmiş kapsam analizi yöntemi ile ortaya çıkarmayı amaçlamıştır. Gülsün ve Erdoğmuş (2021), çalışmalarında bulanık AHP ve bulanık TOPSIS metotlarını bankacılık sektöründe bir finansal analiz yapabilmek için kullanmıştır. Zile (2015), çalışmasında iş sağlığı ve güvenliği alanında bir sorunu ele alarak bulanık mantığı baz alarak bir bilgisayar programı geliştirmiş ve risk değerleme analiz modeli oluşturmuştur. Sirisawat ve Kiatcharoenpol (2018), yaptıkları çalışmada bulanık AHP ve bulanık TOPSIS yöntemlerinden yararlanarak elektronik endüstrisi için; her bir bariyerin ağırlığını çift yönlü karşılaştırıp, tersine lojistik alanında da ağırlıkları sıralama metodolojisi önermişlerdir. Heo ve ark., (2010), genişletilmiş bulanık AHP kullanarak, yenilenebilir enerji yayma programı değerlendirmesi için değerlendirme faktörlerinin analizini belirlemeyi amaçlamışlardır. Taylan ve ark., (2014) inşaat projelerini ve bunların tamamlanmamış, belirsiz durumlardaki genel risklerini değerlendirmek için analitik araçları kullanmayı amaçlamışlardır. Aynı zamanda riski uygun bir kategoriye

\footnotetext{
${ }^{1}$ Sorumlu Yazar. Tel.: +90-322-338-6084-129
}

E-posta adresi: ktumay@cu.edu.tr 
yerleştirmek ve stratejileri geliştirmek aynı zamanda da yüksek risk faktörlerini ortadan kaldırmaya çalışmışlardır. Bu çalışmayı yaparken fuzzy AHP ve fuzzy TOPSIS metotlarından yararlanmışlardır. Li ve ark., (2018), bulanık kümeyi kullanarak ve kural tabanlı bir karar destek mekanizması geliştirerek, işletmelerde nesnelerin internetinde etkili olan faktörleri bulanık AHP analizi ile değerlendirmek için teori geliştirmişlerdir. Dozic ve ark., (2018), bulanık AHP metotunu kullanarak yolcu uçak tipi seçimi için piyasa koşullarına ve havayolu şirketinin gereksinimlerini karşılayan uçak tiplerini seçen yaklaşım geliştirmişlerdir. Akkaya ve ark., (2015), endüstri mühendisliği sektörünün sorununa yönelik entegre bir bulanık AHP ve bulanık MOORA yaklaşımı uygulayarak gelecekte seçilebilecek ve revaçta olabilecek sektörleri değerlendirmek amacıyla kriterler belirleyerek bir çalışma yapmışlardır. Junior ve ark., (2014), bulanık AHP ve bulanık TOPSIS yöntemleri arasında bir karşılaştırma yaparak tedarikçi seçimi için model oluşturmaya çalışmışlardır. Sharma ve ark., (2018), sürdürülebilir gıda sektöründe tedarik zinciri yönetiminin geliştirilmesi amacıyla, güvenlik ve güvenliği artırmak için bulanık AHP metotu kullanarak başarı faktörlerini sıralamaya çalışmışlardır. Beşikçi ve ark., (2016), denizcilik endüstrisinde gemilerin yakıt tüketiminin düşürülmesi amacıyla bulanık AHP metotu kullanılarak operasyonel enerji verimliliğine sevk edilebilir önlemler almaya çalışmışlardır. Calabrese ve ark., (2018), sürdürülebilirliği stratejik karar alma sürecine bulanık AHP metotu ile entegre ederek sürdürülebilirlik konularının seçimi için yöntem geliştirmeyi amaçlamışlardır.

Li ve Wei (2018), dağıtım sistemlerinin seçim problemini çözebilmek için kriterler belirleyerek AHP metotu ve THOWA metotuna dayanan yeni karma bir yöntem önermişlerdir. Mandic ve ark., (2014), Sırp bankalarının mali parametrelerinin analizini yapabilmek için bulanık AHP ve TOPSIS yöntemlerini uygulamışlardır. Çalışmalarındaki amaç finansal performansın değerlendirilmesini kolaylaştıracak bulanık çok kriterli bir model önermektir. Li ve ark., (2018), çalışmalarında; performans biçimlendirme faktörleri ilişkisinin ağırlıklarını belirleyebilmek ve bulanık mantıkla analitik hiyerarşi süreci güvenilirliğini daha objektif olarak değerlendirmek için bulanık AHP temelli bir yöntem oluşturulmuşlardır. Gupta (2018), kuruluşların performansını yeşil insan kaynakları yönetiminin rolü, çevre yönetiminde ve yeşil yönetimde uygulamaları temelinde değerlendirmek amacıyla üç fazlı bir metodoloji kullanarak son aşamasında bulanık TOPSIS metotu ile sipariş tercihi belirlemeyi amaçlamışlardır. Abdel Basset ve ark., (2019), tedarik zincirindeki riskleri ölçmek için nötrofilik analitik hiyerarşi süreci (N-AHP) ve (N-TOPSIS) entegre bir şekilde kullanarak risk yönetimi üzerinde önemli bir etkisi olan belirsiz ve eksik bilgiler için eşleştirme yapmak amaçlanmıştır. Pandey ve ark., (2017), birleştirilmiş bulanık AHP ve bulanık DEMATEL metotuna dayanan, insan kaynakları ve teknoloji kriterlerinin değerlendirilmesine ilişkin bir yaklaşım önermişlerdir. Ligus ve Peternek (2018), yapmış oldukları çalışmada bulanık AHP-TOPSIS yöntemlerini entegre bir şekilde kullanarak Polonya'da en uygun düşük emisyonlu enerji teknolojileri gelişiminin belirlemeye çalışmışlardır. Shahab ve ark., (2018), çevresel analiz çalışmalarında, seçimlerin uygunluğunu incelemek için çok kriterli karar verme yöntemleri kullanılmıştır. Seçim kriterlerinin ağırlıklandırılmasında Delphi Analitik Hiyerarşi Prosesi (DAHP) kullanılmış ve en karlı adayları belirlemek için fuzzy TOPSIS yaklaşımı kullanılarak sonuçları yorumlanmıştır. Moktedir ve ark., (2018), kurumsal sosyal sorumluluk sürücülerinin önceliklendirilmesi amacıyla, gelişmekte olan bir ayakkabı sektöründe bulanık AHP yaklaşımı uygulayarak önceliklendirme sonuçlarını tartışmışlardır. Abdel-Basset ve ark., (2019), yapmış oluğu çalışma çok kriterli karar verme tekniklerinden AHP ve bulanık TOPSIS yöntemlerini kullanarak petrol alanları gelişimi için proje seçimi ile ilgili öneriler geliştirmiş, sonuçları yorumlamıştır. Kapsamlı literatür çalışması sonucunda çok kriterli karar verme metotlarının çok farklı alanlarda başarılı bir şekilde uygulandığı görülmektedir. Günümüz salgın koşulları ve aşı yaptırmanın zorunluluğu göz önünde bulundurulduğunda, aşı merkezlerinin seçimini etkileyen faktörlerin belirlenebilmesi ve nihai aşı merkezlerinden birine karar verebilmenin önemi artmıştır. Yapılan bu çalışmada, tüm koşullar ele alınarak aşı merkezlerinin yoğunluğunu etkileyen kriterlerin belirlenmesinin yanında kişilerin aşı merkezi seçimini kolaylaştırabilecek bir çözüm yöntemi önermek amaçlanmıştır. Böylece; literatürdeki karar verme yöntemlerinden ve incelenen konulardan farklı olarak, bulanık ELECTRE I metodu ile aşı merkezlerinin yoğunluğunu etkileyen faktörler belirlenmiş ve aşı merkezlerinin efektif bir şekilde seçilebilmesi konusu ilk kez ele alınmıştır.

\section{Materyal ve Yöntem}

Çalışmada kişilerin aşı yaptırmak için hangi faktörleri göz ardı edip hangilerini daha önemli buldukları analiz edilmiştir. Kriterlerin belirlenmesi için sağlık personelleri ve aşıyı yaptırmış ve aşıyı yaptıracak olan kişilerin görüşleri alınmıştır ve dokuz adet kriter belirlenmiştir. Tüm bunların neticesinde kişilerin aşı yaptırmak için sağlık ocağını mı, hastaneyi mi yoksa alışveriş merkezlerini mi tercih edeceği araştırılmıştır. Alternatif kurumlar $A_{1}=$ Sağlık ocağ ${ }_{1}, A_{2}=$ Hastane, $A_{3}=A_{1}$ ısveriş merkezi olarak adlandırılmıştır. Kriterler ise; $\mathrm{K}_{1}$ : Kurumun Kalabalık olması, $\mathrm{K}_{2}$ : Aşının çeşidi, $\mathrm{K}_{3}$ : Kuruma olan uzaklık ve ulaşım koşulları, $\mathrm{K}_{4}$ : Ortamın sterilizasyonu, $\mathrm{K}_{5}$ : Çalışan personelin tavrı, $\mathrm{K}_{6}$ : Aşı sonrası bekleme koşulları, $\mathrm{K}_{7}$ : Aşı sonrası olası müdahale durumu, $\mathrm{K}_{8}$ : Kişinin yaşı $\mathrm{K}_{9}$ : Kişinin cinsiyeti olarak belirlenmiştir. Kriterler belirlendikten sonra bulanık ELECTRE I uygulanarak kişilerin ağırlıkla hangi kurumu tercih edebileceği bulunmuştur.

\subsection{Bulanık Mantık}

Belirsizlik durumlarında temel rol oynayan karar verme teorisi olasılıksal durumlarda etkili bir yöntem olmayabilir. Bu durumlarda bulanık mantık teorisi devreye girer ve karar verme sürecini kolaylaştırabilir (Ligus ve Peternek, 2018) Zadeh (1968), belirsizlik altında karar verme durumlarında ' 0 ' ve ' 1 ' üyelik derecelerinin yetersiz olacağını ifade etmiş ve yeni bir teori öne sürmüştür. Üyelik değerlerinin sadece ' 0 ' ve ' 1 ' olarak değil arasındaki değerleri de alabileceğini vurgulayarak [0,1] olarak ifade etmiştir. Buckly'nin teorisi üç parametreli gösterime dayanan; ' 1 ' en az olası değer, 'm' en olası değer ve 'u' ise en çok olası değer olarak ifade edilen üçgensel üyelik fonksiyonu denklemidir. Bu eşitlik Denklem 1'deki gibi hesaplanabilir (Capocelli ve De Luca, 1973). 


$$
\mu_{A}(x ; l ; m ; u)=\left\{\begin{array}{r}
\frac{(x-l)}{(m-l)}, 1 \leq x<m \\
(u-x) /(u-m) m \leq x \leq u \\
0, x>u, x<l
\end{array}\right.
$$

\subsection{Bulanık ELECTRE I}

Bulanık ELECTRE'de dilsel tercihler kolaylıkla bulanık sayılara dönüştürülebilir. Başka bir ifadeyle, ELECTRE değerlendirme sürecinde bulanık sayıları kullanan karar verme tek bir değer üzerinden değildir. Bir bulanık sıralama ilişkisi, k s 1, olmak üzere, bulanık ELECTRE üzerinde her bir alternatif çift $\left(\mathrm{A}_{\mathrm{k}}, \mathrm{A}_{\mathrm{l}}\right)$ ile ilişkili sıralama seviyesini gösteren bir üyelik fonksiyonu (k, l) ile karakterize edilebilir (Wu ve Chen, 2011). Bulanık ELECTRE'ye ait adımlar sırasıyla açıklanmıştır.

1. Adım: Kriterlerin ağırlıkları belirlenmesi: İlk aşamada karar vericiler, önemlerine göre kriter ağırlığını belirler. Daha sonra bu ağırlıklar, bulanık üçgen sayılara çevrilir ve Denklem (1) deki gibi hesaplanır

$$
\begin{aligned}
& \mathrm{w}_{\mathrm{j}}=\left(\mathrm{l}_{\mathrm{j}}, \mathrm{m}_{\mathrm{j}}, \mathrm{u}_{\mathrm{j}}\right) . \\
& \mathrm{l}_{\mathrm{j}}=\min _{\mathrm{k}}\left\{\mathrm{y}_{\mathrm{jk}}\right\} \quad \mathrm{mj}=1 / k \sum_{k=1}^{k} y j k \quad \mathrm{u}_{\mathrm{j}}=\max _{\mathrm{k}}\left\{\mathrm{y}_{\mathrm{jk}}\right\}
\end{aligned}
$$

Ardından, her bir kriter için bulanık önem ağırlıkları Denklem (2) ve Denklem (3) uygulanarak normalleştirilir:

$$
\begin{aligned}
& \hat{\mathrm{W}}=\left(\mathrm{w}_{\mathrm{j}}{ }^{1}, \mathrm{w}_{\mathrm{j}}{ }^{2}, \mathrm{w}_{\mathrm{j}}{ }^{3}\right) \\
& \mathrm{w}_{\mathrm{j}}{ }^{1}=\frac{1 / l j}{\sum_{j=1}^{n} 1 / l j} \quad \mathrm{w}_{\mathrm{j}}{ }^{2}=\frac{1 / m j}{\sum_{j=1}^{n} 1 / m j} \quad \mathrm{w}_{\mathrm{j}}{ }^{3}=\frac{1 / u j}{\sum_{j=1}^{n} 1 / u j}
\end{aligned}
$$

2. Adım: Karar matrisi (X) oluşturulur

$\mathrm{X}=\left[\begin{array}{ccc}x_{11} x_{12} & \cdots & x_{1 n} \\ \vdots & \ddots & \vdots \\ x_{m 1} x_{m 2} & \cdots & x_{1 m}\end{array}\right]$

Burada $\mathrm{i}=1,2, \ldots, \mathrm{m} ; \mathrm{j}=1,2, \ldots, \mathrm{n}$ ve $\mathrm{x}_{\mathrm{ij}}=(\mathrm{i})$ kriterinin $(\mathrm{j})$ alternatifinin değerini ifade etmektedir.

3. Adım: Normalize matrisin oluşturulması: Karar matrisi oluşturduktan sonra normalleştirme işlemi Denklem (6) ve Denklem (7) deki gibi yapılır.

$$
\begin{aligned}
& \mathrm{r}_{\mathrm{ij}}=\frac{x i j}{\sqrt{\sum_{j=1}^{m} x i j 2}} \\
& \mathrm{R}=\left[\begin{array}{ccc}
r_{11} r_{12} & \cdots & r_{1 n} \\
\vdots & \ddots & \vdots \\
r_{m 1} r_{m 2} & \cdots & r_{m n}
\end{array}\right]
\end{aligned}
$$

Burada;

$\mathrm{r}_{\mathrm{ij}}=$ Alternatifler (i) ve kriterlerden (j) seçim ölçümlerinin normalleştirilmesi

$\mathrm{X}_{\mathrm{ij}}=$ (i) kriterinin (j) alternatifinin değeri

$\mathrm{m}=$ alternatif sayısı 
$\mathrm{n}=$ kriter sayısını ifade etmektedir.

4. Adım: Normalize edilen matrisin ağırlıklandırılması: Normalizasyondan sonra, R matrisinin her bir sütunu, karar verici tarafından belirlenen ağırlıklar $\left(\mathrm{w}_{\mathrm{ij}}\right)$ ile çarpılarak V matrisi oluşturulur. Her bir kriter için normalleştirilmiş matris ağırlı̆̆ gibi tanımlanır:

$\mathrm{W}=\left[\mathrm{W}_{\mathrm{ij}}{ }^{\prime}\right]_{\mathrm{mxn}} \mathrm{i}=1,2, \ldots \mathrm{n}$ için $\quad \mathrm{j}=1,2, \ldots \mathrm{m}$

matris çarpımı şeklinde tüm ağırlıklar $\left(\mathrm{V}^{\mathrm{n}}\right)$ için Denklem (9)' daki gibi hesaplanır.

$\mathrm{V}^{1}=\left[\begin{array}{ccc}v^{1}{ }_{11} v^{1}{ }_{12} & \cdots & v^{1}{ }_{1 n} \\ \vdots & \ddots & \vdots \\ v^{1}{ }_{m 1} v^{1}{ }_{m 2} & \cdots & v^{1}{ }_{m n}\end{array}\right]$

Burada;

$\mathrm{V}_{\mathrm{ij}}=\mathrm{V}$ ağırlıklı normalleştirilmiş karar matrisinin elemanı.

$\mathrm{w}_{\mathrm{j}}=\mathrm{j}$. kriterin ağırlı̆

$\mathrm{r}_{\mathrm{ij}}=$ normalleştirilmiş $\mathrm{R}$ karar matrisinin elemanları

$\mathrm{V}^{1}=$ Normalleştirilmiş matrislerin ağırlıklandırılmış halini ifade etmektedir.

5. Adım: Uyum ve uyumsuzluk kümelerinin hesaplanması:

Her alternatif $A_{k}$ ve $A_{1}$ çifti için $(k, l=1,2,3, \ldots, m), j$ kriteri için karar matrisi 2 alt kümeye bölünür.

İlk olarak $\left\{\mathrm{C}_{\mathrm{kl}}\right.$ uyum kümesini ifade etmek üzere $\}$ uyum kümesi, alternatif $\mathrm{A}_{\mathrm{k}}$ 'ın $\mathrm{A}_{1}$ alternatifinden daha iyi olduğu ağırlıklandırma kriterlerinin toplamını gösterir. (Denklem 10).

$\mathrm{C}_{\mathrm{kl}}=\left\{\mathrm{j} \mid \mathrm{v}_{\mathrm{kj}} \geq \mathrm{v}_{\mathrm{j}}\right\} \quad j=1,2, \ldots, n \quad$ için

İkinci olarak, uyumsuzluk kümesi $\left\{\mathrm{D}_{\mathrm{kl}}\right\}$ şu şekilde verilir:

$\mathrm{D}_{\mathrm{kl}}=\left\{\mathrm{j} \mid \mathrm{v}_{\mathrm{kj}}<\mathrm{v}_{\mathrm{lj}}\right\} \quad j=1,2, \ldots, n \quad$ için

Burada;

$\mathrm{C}_{\mathrm{kl}}=$ uyum kümesi

$\mathrm{D}_{\mathrm{kl}}=$ uyumsuzluk seti

$\mathrm{V}_{\mathrm{kj}}=$ matris $\mathrm{V}$ indeksi

$\mathrm{v}_{\mathrm{lj}}=$ matris $\mathrm{V}$ indeksini ifade etmektedir.

6. Adım: Uyum $\left(\mathrm{C}_{\mathrm{pq}}\right)$ ve uyumsuzluk $\left(\mathrm{C}_{\mathrm{pd}}\right)$ indeksinin hesaplanmas1:

$C_{p q}^{1}=\sum_{j *} w_{j 1}$

$C_{p q}^{2}=\sum_{j *} w_{j 2}$

$C_{p q}^{3}=\sum_{j *} w_{j 3}$

Burada $\mathrm{j}^{*}$, uygunluk setine dahil edilen kriterlerdir. Uyumsuzluk indeksi Denklem (13) ile belirlenmektedir. $D_{p q}^{2}$ ve $D_{p q}^{3}$ 'de Denklem (13) yardımı ile hesaplanmaktadır.

$D_{p q}^{1}=\frac{\sum_{j}+\mid v_{p j^{+}-}^{1} v_{q j^{+}}^{1}}{\sum j \mid v_{p j-}^{1} v_{q j}^{1}}$ 
7.Adım: Nihai uyum ve uyumsuzluk indeksleri belirlenerek alternatiflerin sıralaması yapılır:

Denklem (14)'ün durulaştırma işlemi olduğu söylenebilir, nihai uyum değeri diğer alternatiflerden daha büyük ve nihai uyumsuzluk değeri daha küçük ise bir alternatif daha iyi olacaktır. Nihai uyum $\left(C_{p q}^{*}\right)$ ve uyumsuzluk $\left(D_{p q}^{*}\right)$ aşağıdaki Denklem $(14)$ kullanılarak hesaplanabilir. Denklem (15)'de belirtilen formül ile de alternatifler siralanır.

$$
\begin{aligned}
& C_{p q}^{*}=\sqrt[z]{\prod_{z=1}^{z} C_{p q}^{z}} \\
& D_{p q}^{*}=\sqrt[z]{\prod_{z=1}^{z} D_{p q}^{z}} \\
& \mathrm{C}(\mathrm{p}, \mathrm{q}) \geq \mathrm{C} \text { dan } \mathrm{D}(\mathrm{p}, \mathrm{q}) \leq \mathrm{D}
\end{aligned}
$$

\section{Araştırmanın Bulguları}

Kurulan hiyerarşik yapıya göre, belirlenen dokuz kriter ile üç alternatif kurumun seçimi bulanık sayıların karşılığ değerinde yapılmıştır. Yapılan anketlerde ölçek olarak likert kullanılmış ve bulanık sayı eşdeğerlikleri Tablo 1'deki gibi alınmıştır. (Özçakar ve Demir, 2011).

Tablo 1. Karar kriterlerinin sözel ifadeler ve üçgensel bulanık sayı değerleri

\begin{tabular}{ll}
\hline Sözel İfadeler & $\begin{array}{c}\text { Üçgensel Bulanık } \\
\text { Sayı Karşıllk } \\
\text { Değerleri }\end{array}$ \\
\hline Çok iyi & $(9,10,10)$ \\
\hline İyi & $(7,9,10)$ \\
\hline Orta İyi & $(5,7,9)$ \\
\hline Orta & $(3,5,7)$ \\
\hline Orta Kötü & $(1,3,5)$ \\
\hline Kötü & $(0,1,3)$ \\
\hline Çok Kötü & $(0,0,1)$ \\
\hline
\end{tabular}

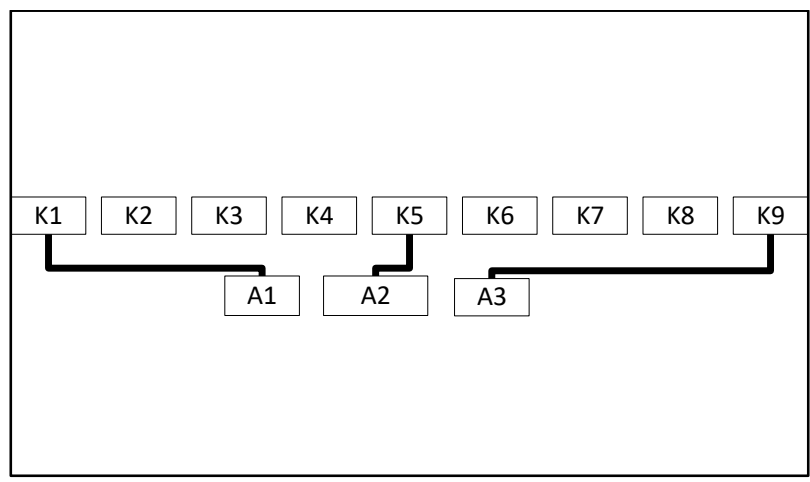

Şekil 1. Alternatif kurum seçiminin şematik gösterimi

Problemin tanımlanması ve kriterlerin belirlenmesinden sonra alternatif kurumların ağırlıklı seçim önceliklerine ait şema K :kriterler A: Alternatif kurum olmak üzere Şekil 1'deki gibi verilmiştir. Problemin tanımına göre belirlenen dokuz kriterin kişilerin alacağı kararı nasıl etkileyeceğini ölçmeye çalışmaktır. $\mathrm{A}_{1}, \mathrm{~A}_{2}$ ve $\mathrm{A}_{3}$ kriterlerin hiyerarşik yapısına göre sembolik olarak belirtilmiştir.

Problem için öncelikle kriterlerin ağırlıkları belirlenmiştir. Bu aşamada karar vericiler, kendi fikirlerine göre anketi puanlar. Daha sonra bu ağırlıklar, bulanık üçgen sayılara çevrilir ve Denklem (1) deki gibi hesaplanır.

Tablo 2'de Bulanık ELECTRE I' in 1. Adım uygulanarak karar matrisi oluşturulmuştur. Karar matrisinde karar vericiye ait üçgen bulanık sayı değerleri kullanılmıştır.

Tablo 2. Bulanık karar matrisinin kriterler ve alternatifler ile oluşturulması 
Daha sonra Denklem (6) ve Denklem (7) uygulanarak normalize edilmiş karar matrisi Tablo 3'deki gibi elde edilmiştir.

Tablo 3. Alternatif kurumlara ait normalize edilmiş karar matrisi

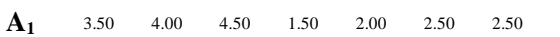
$\begin{array}{llllllll}\mathbf{A}_{2} & 0.67 & 1.00 & 1.50 & 0.67 & 1.00 & 1.50 & 0.67\end{array}$
$\begin{array}{ll}3.50 \quad 0.67 \\ 1.50 & 2.500\end{array}$
$\mathbf{A}_{3}$

\begin{tabular}{lllllllllll}
\hline & $\mathbf{K}_{1}$ & $\mathbf{K}_{\mathbf{2}}$ & $\mathbf{K}_{\mathbf{3}}$ & $\mathbf{K}_{\mathbf{4}}$ & $\mathbf{K}_{\mathbf{5}}$ & $\mathbf{K}_{\mathbf{6}}$ & $\mathbf{K}_{\mathbf{7}}$ & $\mathbf{K}_{\mathbf{8}}$ & $\mathbf{K}_{\mathbf{9}}$ \\
\hline & & & & & & & & & & \\
$\mathbf{A}_{1}$ & 0.9 & 0.7 & 1.1 & 0.4 & 1.1 & 0.9 & 0.8 & 0.4 & 0.4 \\
& & & & & & & & & \\
$\mathbf{A}_{2}$ & 0.4 & 0.4 & 0.4 & 1.1 & 0.4 & 0.4 & 0.2 & 1.1 & 0.4 \\
& & & & & & & & & \\
$\mathbf{A}_{3}$ & 0.4 & 0.3 & 0.4 & 0.4 & 0.4 & 0.7 & 0.3 & 0.4 & 0.9
\end{tabular}

Normalize edilmiş karar matrisinin oluşturulmasının ardından 4. Adım uygulanarak Denklem (8) ve Denklem (9) kullanılarak Tablo 4'deki alternatif kurumlara ait ağırlıklandırılmış karar matrisi elde edilmiştir.

Tablo 4. Alternatif kurumlara ait ağırlıklandırılmış karar matrisi

\begin{tabular}{cccccccccc}
\hline & $\mathbf{K}_{\mathbf{1}}$ & $\mathbf{K}_{\mathbf{2}}$ & $\mathbf{K}_{\mathbf{3}}$ & $\mathbf{K}_{\mathbf{4}}$ & $\mathbf{K}_{\mathbf{5}}$ & $\mathbf{K}_{\mathbf{6}}$ & $\mathbf{K}_{\mathbf{7}}$ & $\mathbf{K}_{\mathbf{8}}$ & $\mathbf{K}_{\mathbf{9}}$ \\
\hline $\mathbf{A}_{\mathbf{1}}$ & 0.00 & 0.00 & 0.27 & 0.13 & 0.05 & 0.11 & 0.00 & 0.08 & 0.01 \\
& & & & & & & & & \\
$\mathbf{A}_{\mathbf{2}}$ & 0.00 & 0.00 & 0.09 & 0.38 & 0.02 & 0.05 & 0.00 & 0.22 & 0.01 \\
& & & & & & & & & \\
$\mathbf{A}_{3}$ & 0.00 & 0.00 & 0.10 & 0.13 & 0.02 & 0.10 & 0.00 & 0.07 & 0.02 \\
\hline
\end{tabular}

Adım 5'in Tablo 4'e uygulanması ile Tablo 5. ve Tablo 6 oluşturulmuştur. Burada Denklem (10) ve Denklem (11) kullanılarak uyum kümeleri matrisi elde edilmiş ve Denklem (12) ile eşik değeri alternatiflerin hesaplanmıştır. Denklem (12) ve Denklem (13) uygunluk kümeleri matrislerine uygulanmış ve uyum indeksi değeri 0.5 elde edilmiştir. 


\begin{tabular}{|c|c|c|c|c|c|c|c|c|c|}
\hline $\mathbf{A}_{1}-\mathbf{A}_{2}$ & 1 & 1 & 1 & 0 & 1 & 1 & 1 & 0 & 0 \\
\hline $\mathbf{A}_{1}-\mathbf{A}_{3}$ & 1 & 1 & 1 & 1 & 1 & 1 & 1 & 1 & 0 \\
\hline $\mathbf{A}_{2}-\mathbf{A}_{1}$ & 1 & 1 & 0 & 1 & 0 & 0 & 1 & 1 & 1 \\
\hline $\mathbf{A}_{2}-\mathbf{A}_{3}$ & 1 & 1 & 0 & 1 & 0 & 0 & 1 & 1 & 0 \\
\hline $\mathbf{A}_{3}-\mathbf{A}_{1}$ & 1 & 1 & 0 & 0 & 0 & 0 & 1 & 0 & 1 \\
\hline $\mathbf{A}_{3}-\mathbf{A}_{2}$ & 1 & 1 & 1 & 0 & 1 & 1 & 1 & 0 & 1 \\
\hline
\end{tabular}

Tablo 6. Alternatif kurumlara ait uyumsuzluk kümesi

\begin{tabular}{|c|c|c|c|c|c|c|c|c|c|}
\hline $\mathbf{A}_{1}-\mathbf{A}_{2}$ & 0.0 & 0.0 & 0.2 & 0.2 & 0.0 & 0.1 & 0.0 & 0.1 & 0.0 \\
\hline $\mathbf{A}_{1}-\mathbf{A}_{3}$ & 0.0 & 0.0 & 0.2 & 0.0 & 0.0 & 0.0 & 0.0 & 0.0 & 0.0 \\
\hline $\mathbf{A}_{2}-\mathbf{A}_{1}$ & 0.0 & 0.0 & 0.2 & 0.2 & 0.0 & 0.1 & 0.0 & 0.1 & 0.0 \\
\hline $\mathbf{A}_{2}-\mathbf{A}_{3}$ & 0.0 & 0.0 & 0.0 & 0.3 & 0.0 & 0.0 & 0.0 & 0.1 & 0.0 \\
\hline $\mathbf{A}_{3}-\mathbf{A}_{1}$ & 0.0 & 0.0 & 0.2 & 0.0 & 0.0 & 0.0 & 0.0 & 0.0 & 0.0 \\
\hline $\mathbf{A}_{3}-\mathbf{A}_{2}$ & 0.0 & 0.0 & 0.0 & 0.3 & 0.0 & 0.0 & 0.0 & 0.1 & 0.0 \\
\hline
\end{tabular}

Uygunluk ve uyumsuzluk kümelerinin belirlenmesinden sonra uyum ve uyumsuzluk matrisi Tablo 7'deki gibi elde edilmiştir.

Tablo 7. Alternatif kurumlara ait uyum ve uyumsuzluk matrisleri

\begin{tabular}{llll}
\hline & $\mathbf{A}_{\mathbf{1}}$ & $\mathbf{A}_{\mathbf{2}}$ & $\mathbf{\mathbf { A } _ { 3 }}$ \\
\hline $\mathbf{A}_{\mathbf{1}}$ & 0 & 0.59 & 0.04 \\
$\mathbf{A}_{\mathbf{2}}$ & 0.40 & 0 & 0.12 \\
$\mathbf{A}_{3}$ & 0.88 & 0.84 & 0 \\
\hline
\end{tabular}

7.Adım'da bulunan Denklem (14), Tablo 7'ye uygulanarak durulaştırma işlemi yapılmış ve nihai uyum indeksleri 0.48 olarak elde edilmiştir. Denklem (15) kullanılarak, Tablo 7'deki tüm alternatiflerin değerleri uyum indeksi değeri ile kıyaslanarak Tablo 8 elde edilmiştir. 


\begin{tabular}{cccc}
\hline & $\mathbf{A}_{1}$ & $\mathbf{A}_{2}$ & $\mathbf{A}_{3}$ \\
\hline $\mathbf{A}_{1}$ & 0 & 0 & 1 \\
$\mathbf{A}_{2}$ & 1 & 0 & 1 \\
$\mathbf{A}_{3}$ & 0 & 0 & 0 \\
\hline
\end{tabular}

Tüm adımların tamamlanmasından sonra Tablo 8'e göre alternatiflerin sırası $A_{2}>A_{1}>A_{3}$ olarak elde edilmiştir. $A_{2}$ : kişilerin aşılama için hastaneyi tercih etmesi ağılıklı olarak ilk sırada yer almıştır. İkinci sırada tercih edilen kurum-yer $\mathrm{A}_{1}$ : sağlık ocakları olmuştur. Son olarak ise $\mathrm{A}_{3}$ : alışveriş merkezlerinin tercih edilmesi son sırada yer almıştır. Tüm sonuçlar değerlendirildiğinde kişilerin belirlenen faktörler dahilinde hastaneleri daha öncelikli olarak tercih ettiği görülmüsstür.

\section{Tartışma ve Sonuç}

Salgın hastalığın çıkmasının ardından aşılama çalışmalarının başlaması ile bir takım aksaklıklar gündeme gelmiştir. Ortaya çıan bu durum sonucunda aşı yapan kişiler ve aşı olan kişiler zaman zaman bulundukları aşı merkezlerinin koşullarından endişe duyabilmektedir. Aynı zamanda aşı yapılan merkezlerin o anki şartları kişilerin aşı yapıp yaptırmayacağı kararını da etkilemektedir. Aşı yaptıracak olan kişilerin kaygılarının yanında dünya genelinde aşılama hızının yavaşlaması bazı aşı merkezlerindeki yoğunlukları da değiştirebilmektedir. Bu durum zaman zaman ülkemizdeki belirlenmiş olan üç farklı aşı merkezinin durumunu da etkileyebilmektedir. Stabil olmayan bu durum karşısında aşı olacak kişinin randevusunu alırken neleri kriter olarak aldığı ve aşı yaptırmadan önce kararını hangi faktörlerin etkilediği araştııılmıştır. Aşılanacak kişiler, kimi zaman aşı yaptıran kişilerin olumsuz deneyimlerinden etkilenerek aşı merkezi seçimi esnasında kendilerine zorluk yaratabilmekte ya da aşı olmayı erteleyebilmektedirler. Bütün bu olumsuz durumlar ön planda tutularak ve aşı yaptıracak kişilerin duygu durum ve düşünceleri de göz önünde bulundurularak, aşı merkezlerinin seçimi esnasında hangi kriterlerin daha öncelikli olduğu çalışmanın önemini arttırmıştır. Böylelikle içinde bulunulan koşulların iyileştirilebilmesi ve aşı yaptıracak olan kişilerin kaygılarının azaltılabilmesi mümkün olabilecektir. İyileşen bu durum karşısında aşı olacak kişilerin aşı merkezlerini seçerken daha rahat ve daha tereddütsüz olabilecektir.

Böylelikle; bu çalışmada çok kriterli karar verme yöntemlerinden biri olan Bulanık ELECTRE I yöntemi ile aşı yaptıracak olan kişilerin hangi faktörler doğrultusunda hangi kuruma gittiği analiz edilmeye çalışılmıştır. Kriterlerin $\mathrm{K}_{1}$ : Kurumun Kalabalık olması, $\mathrm{K}_{2}$ : Aşının çeşidi, $\mathrm{K}_{3}$ : Kuruma olan uzaklık ve ulaşım koşulları, $\mathrm{K}_{4}$ : Ortamın sterilizasyonu, $\mathrm{K}_{5}$ : Çalışan personelin tavrı, $\mathrm{K}_{6}$ : Așı sonrası bekleme koşulları, $\mathrm{K}_{7}$ : Aşı sonrası olası müdahale durumu, $\mathrm{K}_{8}$ : Kişinin yaşı $\mathrm{K}_{9}$ : Kişinin cinsiyeti olarak belirlenmesinin ardından, aşı yapılan üç farklı alternatif kurum-yer karar vericiye bırakılmıştır. Karar vericinin hangi faktörler neticesinde hangi kuruma-yere gideceği alternatif seçim anlayışı ile belirlenmiştir. Bulanık ELECTRE I'in tüm adımlarının tamamlanmasından sonra sonuçlara bakıldığında; aşı yaptırmak isteyen kişilerin hastaneleri ağılıklı olarak ilk sırada tercih etmişlerdir. Diğer bir yer olan sağlık ocağını ise ikinci ağırlıkla, alışveriş merkezlerinin ise üçüncü ağırlıkla tercih edildiği görülmüştür.

$\mathrm{Bu}$ çalışma neticesinde alternatif kurumların-yerlerin sırası $\mathrm{A}_{2}-\mathrm{A}_{1}-\mathrm{A}_{3}$ olarak belirlenmiştir. Yapılan bu analiz sonucunda içinde bulunduğumuz dönemdeki pandemi koşullarının iyileşmesi söz konusu olabilecek ve teknik aksaklıkların giderilmesi kolaylaşabilecektir. Bu çalışma sonrasında yapılacak olan çalışmalar için farklı karar verme yöntemleri kullanılarak karşılaştırmalar yapılabilir. Aynı zamanda birden fazla bulanık mantık süreci kullanılarak alternatif yaklaşımlar önerilebilir.

\section{Referanslar}

Abdel-Basset, M., Gunasekaran, M., Mohamed M, \& Chilamkurti N, (2019). A framework for risk assessment, management and evaluation: Economic tool for quantifying risks in supply chain. Future Generation Computer Systems, 90: 489-502.

Akkaya G, Turanoğlu, B. \& Öztaş, S., (2015) An integrated fuzzy AHP and fuzzy MOORA approach to the problem of industrial engineering sector choosing, Expert Systems with Applications, 42(24): 9565-9573.

Akram, M., Garg, H. \& Zahid K. (2020). Extensions of ELECTRE-I and TOPSIS methods for group decision-making under complex Pythagorean fuzzy environment. Iranian Journal of Fuzzy Systems, 17(5):147-164.

Alizadeh, S., Rad, MMS., \& Bazzazi, A.A. (2016). Alunite processing method selection using the AHP and TOPSIS approaches under fuzzy environment. International Journal of Mining Science and Technology, 26(6): 1017-1023,

Beşikçi, E.B., Kececi, T., Arslan., O, \& Turan O, (2016). An application of fuzzy-AHP to ship operational energy efficiency measures. Ocean Engineering, 121: 392-40. 
Buckley, J.J., (1985). Fuzzy hierarchical analysis, Fuzzy sets and systems, 17(3):233-247.

Calabrese, A., Costa, R., Levialdi, N., Menichini, T. (2018). Integrating sustainability into strategic decision-making: A fuzzy AHP method for the selection of relevant sustainability issues, Technological Forecasting and Social Change.

Capocelli, R.M., De Luca, A. (1973). Fuzzy sets and decision theory, Information and control, 23(5): 446-473.

Cihan, P. (2021). Forecasting fully vaccinated people against COVID-19 and examining future vaccination rate for herd immunity in the US, Asia, Europe, Africa, South America, and the World. Applied Soft Computing, 111: 107708.

Dožić, S. (2018). Lutovac, T. ve Kalić, M. Fuzzy AHP approach to passenger aircraft type selection. Journal of Air Transport Management, 68: 165-175.

Gupta, H. (2018). Assessing organizations performance on the basis of GHRM practices using BWM and Fuzzy TOPSIS. Journal of environmental management, 226: 201-216.

Güler, M.E. (2012). Prioritization of Revenue Management Factors: A Synthetic Extent Analysis Approach/Getiri Yönetimi Faktörlerinin Önceliklendirilmesi: Sentetik Kapsam Analizi Yaklasimi, Ege Akademik Bakis, 12(2): 161.

Gülsün, B., Erdoğmuş, K,N. (2021). Bankacılık Sektöründe Bulanık Analitik Hiyerarşi Prosesi ve Bulanık TOPSIS Yöntemleri ile Finansal Performans Değerlendirmesi. Süleyman Demirel Üniversitesi Fen Bilimleri Enstitüsü Dergisi, 25(1): 1-15.

Heo E, Kim J, Boo K-J, (2010). Analysis of the assessment factors for renewable energy dissemination program evaluation using fuzzy AHP. Renewable and Sustainable Energy Reviews, 14(8): 2214-2220.

Junior FRL, Osiro L, ve Carpinetti LCR, (2014). A comparison between Fuzzy AHP and Fuzzy TOPSIS methods to supplier selection, Applied Soft Computing, 21: 194-209.

Li P, Zhang L, Dai L, Zou Y, Li X, (2018). An assessment method of operator's situation awareness reliability based on fuzzy logic-AHP. Safety Science.

Li S, Wei \& Z, (2018). A hybrid approach based on the analytic hierarchy process and 2-tuple hybrid ordered weighted averaging for location selection of distribution centers. PloS one, 13(11):e0206966.

Ligus M, \& Peternek, P. (2018). Determination of most suitable low-emission energy technologies development in Poland using integrated fuzzy AHP-TOPSIS method, Energy Procedia, 153: 101-106.

Ly PTM, Lai WH, Hsu CW, Shih FY, (2018). Fuzzy AHP analysis of Internet of Things (IoT) in enterprises. Technological Forecasting and Social Change, 136: 1-13.

Mandic K, Delibasic B, Knezevic S, Benkovic S (2014). Analysis of the financial parameters of Serbian banks through the application of the fuzzy AHP and TOPSIS methods. Economic Modelling, 43: 30-37.

Moktadir A, Rahman T, Jabbour CJC, Ali SM, Kabir G ( 2018).Prioritization of drivers of corporate social responsibility in the footwear industry in an emerging economy: A fuzzy AHP approach. Journal of Cleaner Production, 201:369-381.

Özçakar N, Demir HH, (2011). Bulanık TOPSIS Yöntemi ile Tedarikçi Seçimi. İstanbul Üniversitesi İşletme İktisadı Enstitüsü Dergisi, 22(69): 28-33.

Pandey A, Kumar A, (2017). Commentary on "Evaluating the criteria for human resource for science and technology (HRST) based on an integrated fuzzy AHP and fuzzy DEMATEL approach. Applied Soft Computing, 51: 351-352.

Sharma YK, Yadav AK, Mangla SK Patil PP, (2018). Ranking the Success Factors to Improve Safety and Security in Sustainable Food Supply Chain Management Using Fuzzy AHP, Materials Today: Proceedings, 5(5): 12187-12196.

Sirisawat P, Kiatcharoenpol T, (2018). Fuzzy AHP-TOPSIS approaches to prioritizing solutions for reverse logistics barriers. Computers \& Industrial Engineering, 117:303-318.

Taylan O, Bafail AO, Abdulaal RM, Kabli MR, 2014. Construction projects selection and risk assessment by fuzzy AHP and fuzzy TOPSIS methodologies. Applied Soft Computing, 17: 105-116. 
Wu MC, Chen TY. (2011). The ELECTRE Multicriteria Analysis Approach Based on Atanassov's Intuitionistic Fuzzy Sets. Expert Systems withApplications. 38(10):12318-12327.

Zadeh LA, 1968. Probability measures of fuzzy events, Journal of mathematical analysis and applications, 23(2): 421-427.

Zile M, 2015. İş Güvenliği Risk Değerlendirme Analiz Modellemesi ve Yazılımının Bulanık Mantıkla Oluşturulması. Çukurova Üniversitesi Mühendislik-Mimarlık Fakültesi Dergisi, 30(2): 267-274. 